\title{
Oppositional Defiant Disorder
}

National Cancer Institute

\section{Source}

National Cancer Institute. Oppositional Defiant Disorder. NCI Thesaurus. Code C92565.

A behavior disorder characterized by a persistent pattern of defiant, disobedient, and hostile behavior towards authority figures, manifested by a frequent loss of temper, arguing, becoming angry or vindictive, or other negativistic behaviors. 